Umfrage

\title{
Altenpflege am Limit
}

— Um die Sicht der Pflegefachkräfte auf das Pflegestärkungsgesetz II (PSG II) dreht sich die Umfrage "Altenpflege im Fokus", durchgeführt vom Fachverlag Vincentz Network Altenhilfe gemeinsam mit dem Marktforschungsinstitut cogitaris. Dazu wurden im Herbst 2016727 Pflegekräfte in der stationären Langzeitpflege befragt. Das Resultat zeichnet ein düsteres Bild: Die Umfrageteilnehmer erwarten durch das PSG II steigende fachliche Anforderungen und noch höhere psychische wie auch körperliche Belastungen.

Gleichzeitig gibt die überwiegende Mehrheit der Befragten an, dass es ihnen bereits jetzt unter den heutigen Rahmenbedingungen schwer fällt, gute Pflege zu gewährleisten. „Die Umfrage macht deutlich, wie sehr die Altenpflegerinnen und Altenpfleger bereits am Limit sind", sagte Monika Gaier von Vincentz Network Altenhilfe bei der Vorstellung der Ergebnisse in Berlin. „Ohne wirksame Maßnahmen gegen den Fachkräftemangel, ohne Absicherung der notwen-

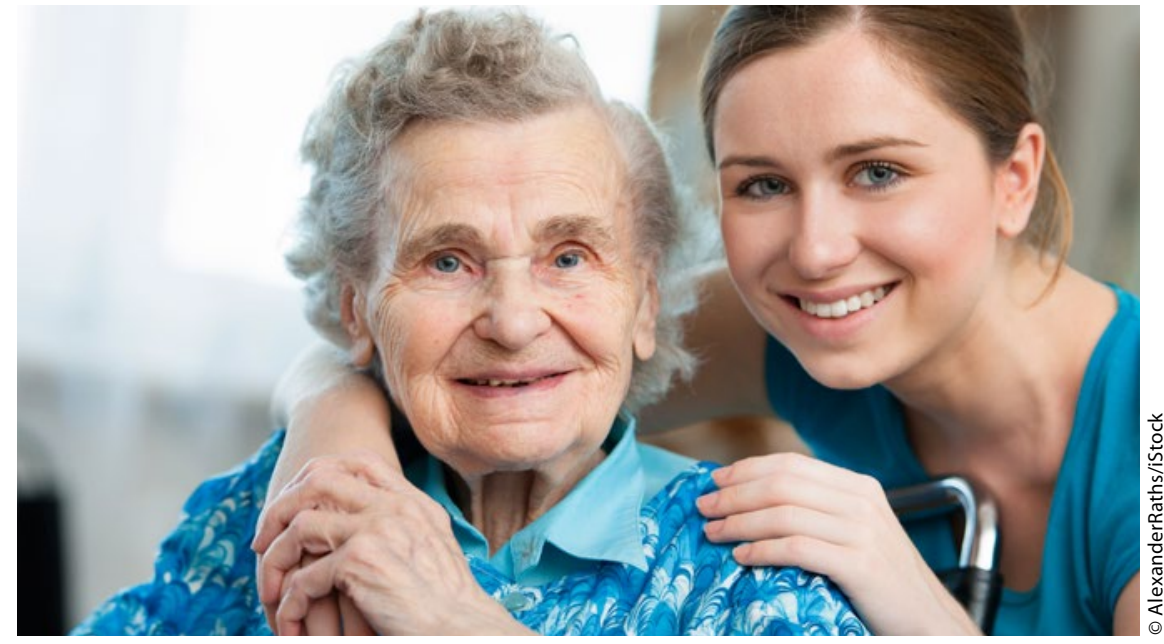

Wird menschliche Zuwendung die Ausnahme?

digen Personalschlüssel, wird die Reform die Situation in der stationären Altenhilfe weiter verschärfen", so Gaier weiter.

Aus der Befragung geht hervor, wie sehr die Pflegefachkräfte bereits jetzt unter dem Fachkräftemangel und den durch das PSG II drohenden Mehrbelastungen leiden. Auf die Frage, welche Maßnahmen den Personalmangel lindern könnten, antworten die Befragten eindeutig: Die Bezahlung muss erhöht und ein bundesweit einheitlicher Personalschlüssel auf Basis eines Personalbemessungsverfah- rens geschaffen werden. Eine weitere Forderung ist die bessere Vereinbarkeit von Beruf und Familie. Ziel der Umfragen ist, die Sicht der professionellen Pflege auf die gegenwärtigen Herausforderungen in der Branche wiederzugeben. Das Altenpflegebarometer hatte im Juni 2016 gezeigt, dass 86\% der Führungskräfte der stationären Altenpflegeeinrichtungen mit der Altenpflegepolitik der Bundesregierung unzufrieden sind.

www.vincentz.net

\section{Bundeswettbewerb}

\section{Wer wird bester Schüler 2017?}

— Bereits zum siebten Mal findet in diesem Jahr der Bundeswettbewerb „Bester Schüler in der Alten- und Krankenpflege“ statt, organisiert vom Verein zur Förderung pflegerischer Qualität. Im Februar und März finden die Vorentscheide in Dresden, Scheinfeld in Bayern, Lüneburg und Köln statt. Jede Alten- und Krankenpflegeschule ist eingeladen, sich anzu-

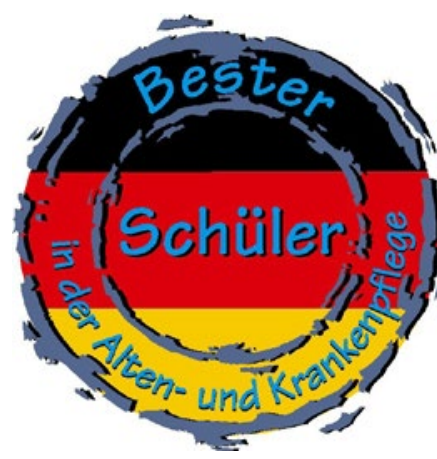
melden und ihre besten Schüler zu den Vorentscheiden zu schicken. Der Präsident des Vereins, Jens Frieß, freut sich besonders über die Zusage von Dr. Eckart von Hirschhausen, in Köln einen Fachvortrag zu „Humor in der Pflege“ zu halten.

Im Rahmen des Vorentscheids müssen 50 Fragen schriftlich beantwortet werden. Wer sich besser einschätzen möchte, kann sich vorab die Fragen vom Vorjahr auf der Homepage von Heilberufe (www.heilberufe.de) ansehen. Die Klausur dient der Zulassung zum Endausscheid im Mai in Berlin. Dort müssen die Teilnehmer, die eine Runde weiter gekommen sind, zwei praktische Prüfaufgaben lösen. Bewertet wird aber nicht nur die praktische Umsetzung der Aufgabe, sondern auch die zuvor vom Prüfling verfasste Pflegeplanung. Es wird also anstrengend: Die Teilnehmer müssen die Einzelwettbewerbe „Planung pflegerischer Prozesse“, „Pflegepraxis" und das „pflegerische Kolloquium“ bestehen. Doch die Mühe lohnt sich: Dem Gewinner winkt eine Reise nach New York für zwei Personen - und 250 Euro Taschengeld gibt es obendrauf! Auf die Zweit- und Drittplatzierten warten je eine Reise nach London und Berlin.

\section{Alles richtig?}

Die korrekten Antworten der PflegeKollegs lauten:

Sturzrisiko senken

1c, 2a, 3a, 4b, 5c, 6c, 7b, 8a, 9c, 10a

Erkrankungen der Leber $1 b, 2 a, 3 a, 4 b, 5 c, 6 c, 7 a, 8 b, 9 c, 10 b$

Vorschau! Die PflegeKollegs im Monat März:

Risiko Nadelstich Gefährdung - Ereignis - Recht

Inkontinenz

Tabuthema Nr. 1 - Altersschicksal? - IAD 